\title{
The Use of Thermal Analysis and Photoacoustic Spectroscopy in the Evaluation of Maltodextrin Microencapsulation of Anthocyanins from Juçara Palm Fruit (Euterpe edulis Mart.) and Their Application in Food
}

\author{
Ana Paula da Silva dos Passos ${ }^{1}$, Grasiele Scaramal Madrona ${ }^{1}$, Vanessa Aparecida \\ Marcolino ${ }^{2}$, Mauro Luciano Baesso ${ }^{3}$ and Graciette Matioli ${ }^{1 *}$
}

${ }^{1}$ Postgraduate Program in Food Science, State University of Maringá (UEM), Avenida Colombo 5790,

CEP 87020-900, Maringá PR, Brazil

${ }^{2}$ Food Technology Department, Federal Institute for Education, Science and Technology of Paraná (IFPR),

R. José Felipe Tequinha 1400, 87703-536, Paranavaí PR, Brazil

${ }^{3}$ Physics Department, State University of Maringá (UEM), Avenida Colombo 5790,

CEP 87020-900, Maringá PR, Brazil

Received: May 15, 2014

Accepted: June 19, 2015

\begin{abstract}
Summary
Anthocyanins extracted from the pulp of the fruit of juçara palm (Euterpe edulis Mart.) were microencapsulated with maltodextrin in order to stabilise them. Photoacoustic spectroscopy was used to investigate the photostability of the microencapsulated samples. Complementary differential scanning calorimetry and scanning electron microscopy measurements were also performed. Lyophilised extract had $14340.2 \mathrm{mg} / \mathrm{L}$ of total anthocyanins, and the microencapsulation efficiency of $93.6 \%$. Temperature analysis showed that maltodextrin conferred protection up to $70^{\circ} \mathrm{C}$ for $120 \mathrm{~min}$. Scanning electron microscopy showed that the microencapsulated particles had a flake-like morphology with a smooth surface, characteristic of lyophilisation processes. In addition, when added to yogurt, a red colourant was predominant in the samples at $\mathrm{pH}$ from 1.5 up to 5.0. Thermal analysis showed a weak interaction between the sample and the encapsulating agent, and photoacoustic data indicated the photostability of the matrix when exposed to light. Yogurts containing microencapsulated anthocyanins showed a more intense pink colour than yogurts treated with pure dye, and sensory analysis demonstrated that they can have good acceptance on the market. Microencapsulation enabled the innovative application of anthocyanins from juçara palm fruit, and complementary techniques allied to the photoacoustic spectroscopy were effective tools for its evaluation.
\end{abstract}

Key words: anthocyanins, natural colourants, lyophilisation, microencapsulation, juçara palm

\section{Introduction}

Colour is one of the most important quality attributes of food (1). The use of artificial colourants has been justified due to their stability, purity, availability, colour power, low price and uniformity in foods produced on large scale (2). However, it is well recognized that natural colourants have gained worldwide importance focusing on the development of foods free from synthetic compounds (3). Nowadays, natural colourants represent a small portion of the market especially due to the lack of knowledge 
about their physicochemical properties after incorporation in foodstuff, adaptation processes, packaging and distribution, and thus insufficient data about the final product shelf life. To overcame this, the food industry has encouraged the development of new ways to stabilize pigments, such as encapsulation and the addition of antioxidants $(3,4)$. Evaluation of the photostability of these compounds is an important aspect of food colourant application.

Flavonoids are the chemicals that play a major role in the colour of natural products. They are responsible for the colours of leaves and flowers. They can also be present in other parts of the plant (4). Anthocyanins are compounds that belong to the group of flavonoids responsible for the wide variety of colours of fruits and flowers, ranging from red-orange to bright red, purple and blue (5). The juçara palm (Euterpe edulis Mart.) is a native plant of the Atlantic Forest and its consumption has been stimulated by marketing techniques focusing on its functional properties, availability and low cost. The fruits of the juçara palm have more anthocyanins than the açai (Euterpe oleracea Mart.) (6). The juçara pulp is used in the manufacture of juices, chocolates, ice creams, creams and other products.

Anthocyanins are an option for the replacement of artificial colourants, because of their attractive bright colours, high water solubility, and several recognised functional properties, such as reduction of coronary heart disease, stroke risk reduction, anticarcinogenic activity, increased visual acuity and cognitive effects (7). However, anthocyanins, when isolated, are highly unstable and very susceptible to degradation (8). The factors that cause instability and degradation of anthocyanins are $\mathrm{pH}$, light, $\mathrm{O}_{2}$, sulphur dioxide, presence of copigments, self-association, metallic ions, enzymes, ascorbic acid, sugar, proteins and heat (9-11).

Natural colourant stability can be improved by microencapsulation techniques, spray drying, freeze drying, inclusion into complexes and co-crystallization, among others (12). Spray drying is the most commonly applied method in the food industry for obtaining natural colours; however, this technique has limitations such as the loss of volatile compounds and oxidation reactions (7).

The microencapsulation with maltodextrin is a technique in which sensitive compounds are encapsulated by a coating material or wall, protecting them from factors that may cause spoilage, such as light and oxygen. Microencapsulation also increases the lifetime of the compounds and can also control their release $(4,13,14)$. Numerous wall materials can be used in the microencapsulation process. The most commonly used are maltodextrins, which are derived from starch hydrolysates, are highly water soluble, have low viscosity, a pleasant taste and give a colourless solution $(4,7,13)$. Encapsulation studies of anthocyanins from black carrots with maltodextrin through spray drying had been carried out before (11) and the authors found that the maltodextrin behaves as a good wall material. They showed that the encapsulated compounds had an increased half-life when stored at $4{ }^{\circ} \mathrm{C}$.

Several researchers have used thermal analysis techniques, such as thermogravimetric analysis (TGA) and differential scanning calorimetry (DSC) $(15,16)$, to study the behaviour of anthocyanins in the microencapsulation process. Photoacoustic spectroscopy is a nondestructive technique that allows the analysis of samples without the need for prior preparation. Activities such as the extraction process and chemical treatment, among others, are, for the most part, not required, since the method can be used to study samples in the solid, semisolid and powder forms (17).

Considering the current need for stable natural colours for industrial use and the importance of foods enriched with 'functional' compounds, this study aims to stabilise anthocyanins obtained from juçara palm fruit by microencapsulation with maltodextrin. The characterisation was performed using DSC, TGA, scanning electron microscopy and photoacoustic spectroscopy, evaluating the microencapsulation process efficacy and the thermal and photostability of the compounds.

\section{Materials and Methods}

\section{Anthocyanin extraction}

The pulp of fresh fruits of juçara palm (Euterpe edulis Mart.) was provided by the company Solabia Group (Maringa PR, Brazil). The extraction of anthocyanins was performed according to the methods proposed by Teixeira et al. (18), with modifications. The extraction was performed using a 1:2 ratio of the pulp of the juçara palm fruit $(\mathrm{Eu}$ terpe edulis Mart.) to a solution of ethanol and water (7:3) and enough $\mathrm{HCl}$ to adjust the medium to $\mathrm{pH}=2.0$. The mixture was stirred on a magnetic stirrer (model 752; Fisatom, São Paulo, SP, Brazil) for $40 \mathrm{~min}$ and protected from light. After extraction, the mixture was filtered and centrifuged at $2146 \times g$ for $10 \mathrm{~min}$ (CT-5000 centrifuge; Cientec, Piracicaba, SP, Brazil). Using a separatory funnel, the chlorophyll present in the extract was removed by extraction with three successive aliquots of $150 \mathrm{~mL}$ of diethyl ether/petroleum ether (1:1).

The extract was concentrated to $30 \%$ of its initial volume in a rotary evaporator (model TE-211; Tecnal, Piracicaba, SP, Brazil) at $45^{\circ} \mathrm{C}$ with a vacuum pump attached (model TE-058; Tecnal). The extract was protected from light, frozen in liquid nitrogen, lyophilised at $-50{ }^{\circ} \mathrm{C}$ for $24 \mathrm{~h}$ on a bench freeze dryer (Alpha 1-4 LD; Martin Christ Gefriertrocknungsanlagen $\mathrm{GmbH}$, Osterode am Harz, Germany) and stored in a freezer at $-20{ }^{\circ} \mathrm{C}$.

\section{Determination of anthocyanins}

The total anthocyanin content was determined using differential $\mathrm{pH}$, according to the method described by Lee et al. (19) using two buffer systems (Neon, São Paulo, Brazil), one with $0.025 \mathrm{M}$ potassium chloride, $\mathrm{pH}=1.0$, and another with $0.4 \mathrm{M}$ sodium acetate, $\mathrm{pH}=4.5$. The solutions were diluted to obtain absorbances in the range between 0.2 and 1.4, which were measured using a spectrophotometer (model 4001/4; Thermo Electron Corp, Madison, WI, USA) at 520 and $700 \mathrm{~nm}$. The final absorbance was calculated using the following equation:

$$
A_{\text {final }}=\left(A_{520 \mathrm{~nm}}-A_{700 \mathrm{~nm}}\right)_{\mathrm{pH}=1}-\left(A_{520 \mathrm{~nm}}-A_{700 \mathrm{~nm}}\right)_{\mathrm{pH}=4.5}
$$

and the mass concentration of total anthocyanins $(\gamma(\mathrm{TA}))$ by the following equation: 


$$
\gamma(\mathrm{TA})=(A \cdot M \cdot \mathrm{DF} \cdot 1000) /(\varepsilon \cdot 1)
$$

where $M$ is molecular mass, $\mathrm{DF}$ is dilution factor, 1000 is a factor of conversion from $\mathrm{g}$ to $\mathrm{mg}$, 1 is optical path length in $\mathrm{cm}$ and $\varepsilon$ is molar absorption coefficient of cyanidin-3glucoside of $26900 \mathrm{~L} /(\mathrm{mol} \cdot \mathrm{cm})$; the results were expressed in $\mathrm{mg} / \mathrm{L}$.

\section{Preparation of microcapsules}

The microcapsules were prepared at room temperature of $(25 \pm 2){ }^{\circ} \mathrm{C}$ according to the method described by Selim et al. (2), with modifications. Maltodextrin (Fluka, Buchs, Switzerland) with dextrose equivalent of 20 (DE= 20) was used as the encapsulating agent (matrix), and the ratio of lyophilised anthocyanin extract to matrix was 1:10. A mass of $10 \mathrm{~g}$ of matrix was dissolved in $50 \mathrm{~mL}$ of distilled water, and the $\mathrm{pH}$ was adjusted to 2.0 with concentrated hydrochloric acid. Next, $1.0 \mathrm{~g}$ of the lyophilised anthocyanin extract was added to the solution. The mixture was stirred for $15 \mathrm{~min}$, transferred to a flask, frozen in liquid nitrogen, lyophilised and stored in amber bottles in a freezer at $-20^{\circ} \mathrm{C}$.

\section{Efficiency of the microencapsulation process}

To measure the efficiency of the microencapsulation process at room temperature of $(25 \pm 2){ }^{\circ} \mathrm{C}$, total anthocyanins present in the interior and exterior of the complex were analysed. For the analysis of the total microencapsulated anthocyanins, the microcapsule coating was undone according to the procedure proposed by Robert et al. (20), in which $200 \mathrm{mg}$ of microcapsules were placed in test tubes with $2 \mathrm{~mL}$ of methanol/acetic acid/water in a ratio of 50:8:42. The mixture was stirred in a stirrer (model AP 56; Phonex, Araraquara, SP, Brazil) for $1 \mathrm{~min}$, and homogenised in an ultrasonic cleaner with heating (model USC$-1400 \mathrm{~A}$; Unique, Indaiatuba, SP, Brazil) for $20 \mathrm{~min}$. Anthocyanin content was quantified as described above.

For the quantification of anthocyanins on the exterior of the complex, $200 \mathrm{mg}$ of the microcapsules were added to $2 \mathrm{~mL}$ of a 1:1 solution of ethanol and methanol. The mixture was vortexed at room temperature for $1 \mathrm{~min}$ and filtered through a $45-\mu \mathrm{m}$ Swinny stainless steel filter (Millipore Corporation, Bedford, MA, USA). Anthocyanins were determined as described above. The percentage of surface compounds and the efficiency of the microencapsulation process were calculated.

\section{Effect of heat treatment on anthocyanin stability}

The thermal stability of the microencapsulated and lyophilised anthocyanin extracts was determined according to the method proposed by Selim et al. (2), with modifications. An adequate amount of anthocyanins was diluted with citrate phosphate buffer, $\mathrm{pH}=2.0$, and total anthocyanins were determined as previously described. To determine the stability to heating, $10-\mathrm{mL}$ aliquots of the extract were placed in glass tubes with screw caps and heated in a thermostat bath (TE 184, Tecnal) at controlled temperatures of $60,70,80$ and $90^{\circ} \mathrm{C}$ for $30,40,50,60,70$, 80, 90, 100, 110 and $120 \mathrm{~min}$. After the treatments, the tubes were immediately cooled in ice water and the concentrations of anthocyanins were determined.

\section{Effect of $\mathrm{pH}$ on anthocyanin colour stability}

Stability of lyophilised and microencapsulated anthocyanin extracts was tested at the following $\mathrm{pH}$ values: $1.5,2.0,3.0,4.0,5.0,6.0,7.0,8.0$ and 9.0. The analyses were performed as described by Wang et al. (21). In this assay, 2 $\mathrm{mL}$ of each extract were mixed with $5 \mathrm{~mL}$ of Mcllvaine buffer solution (BioWord, Dublin, OH, USA). The samples were placed in glass tubes with screw caps, sealed, packed in aluminium foil and placed in a refrigerator at 8 ${ }^{\circ} \mathrm{C}$. The absorbance of the samples was evaluated during 8 days and the aliquots were sequentially analysed at intervals of $48 \mathrm{~h}$ using a spectrophotometer (model 4001/4; Thermo Electron Corp) at $520 \mathrm{~nm}$.

\section{Complex morphology of maltodextrin and anthocyanins}

The morphologies of maltodextrin particles with $\mathrm{DE}=20$, lyophilised anthocyanin extract and lyophilised anthocyanin extract microencapsulated with maltodextrin with $\mathrm{DE}=20$ were evaluated by scanning electron microscopy (SEM; SuperScan SS-550; Shimadzu, Bangkok, Thailand), following the method described by Laine et al. (14). The samples were gold-coated, placed on a support and the images were taken at magnification of 200x.

\section{Differential scanning calorimetry and thermogravimet- ric analysis}

A mass of $5 \mathrm{mg}$ of anthocyanins, maltodextrin with $\mathrm{DE}=20$ and anthocyanins microencapsulated with maltodextrin with $\mathrm{DE}=20$ was weighed, placed in a platinum crucible and submitted to DSC and TGA. A simultaneous thermal analysis system and dilatometer (STA 409 Luxx $^{\circledR}$ PG/4/C and DIL 402 PC/4; NETZSCH, Selb, Germany) was used at initial and final temperatures of 20 and 500 ${ }^{\circ} \mathrm{C}$, respectively. The heating rate was $10{ }^{\circ} \mathrm{C}$ per min under nitrogen atmosphere with a flow rate of $20 \mathrm{~mL} / \mathrm{min}$.

The yogurt samples without the addition of anthocyanins, with the addition of anthocyanins and with the addition of anthocyanins microencapsulated with maltodextrin were placed in a platinum crucible and subjected to DSC analysis and TGA, as previously described.

\section{Photoacustic spectroscopy of samples}

The lyophilised anthocyanin samples, maltodextrin with $\mathrm{DE}=20$ and anthocyanins microencapsulated with maltodextrin were evaluated by photoacoustic spectroscopy. Likewise, yogurt samples without the addition of anthocyanins, with the addition of anthocyanins and with the addition of anthocyanins microencapsulated with maltodextrin were evaluated.

Photoacoustic spectroscopy eliminates sample preparation, and the sample powder, after lyophilisation, was placed directly into the device. Initially, the absorption spectra of the samples were observed in the UV-Vis regions between 200 and $800 \mathrm{~nm}$. The samples were then illuminated with a white light for $2 \mathrm{~h}$, and the absorption spectra were obtained. The experiments were obtained using light modulation frequency at $25 \mathrm{~Hz}$.

The schematic diagram of the experimental setup of the photoacoustic spectrometer comprises a source of 
monochromatic light from a xenon arc lamp with a power of $700 \mathrm{~W}$ (model 68820; Oriel ${ }^{\circledR}$ Instruments, Newport Corp., Irvine, CA, USA) and a monochromator (model 77250; Oriel ${ }^{\circledR}$ Instruments). The light beam is controlled by a mechanical modulator (model SR540; Stanford Research Systems, Sunnyvale, CA, USA). The photoacoustic cell is a standard model, designed to have a minimum volume. This device consists of machined aluminum block containing a sample chamber with maximum dimensions of $5 \mathrm{~mm}$ in diameter and $1 \mathrm{~mm}$ thick. The light is transmitted through a quartz window and focused inside the photoacoustic cell. The microphone is attached to the photoacoustic cell (model B\&K 2669; Brüel \& Kjaer, Nærum, Denmark) through a duct of $1 \mathrm{~mm}$ in diameter and connected to a power source and a preamplifier. The microphone signal is transferred to the lock-in (synchronized amplifier 5110; EG\&G Instruments, Tulsa, OK, USA) that provides the intensity and phase of the photoacoustic signal, which is transferred to a PC via a general purpose interface bus. The signals from the photoacoustic spectra of the samples were normalized to those from ultrapure carbon powder (22).

\section{Application of anthocyanins in food and colour analysis}

The anthocyanin extract powder obtained after lyophilisation and anthocyanins microencapsulated with maltodextrin were used in the preparation of yogurt. The following three types of yogurt were prepared according to the methods described by Rensis and Souza (23) with some modifications: yogurt with UHT milk (standard) without the addition of anthocyanins, yogurt with the addition of anthocyanins and yogurt with anthocyanins microencapsulated with maltodextrin.

The yogurt was prepared with pasteurised milk, lactic cultures of Streptococcus thermophilus and Lactobacillus bulgaricus (Bio Rich ${ }^{\circledR}$, Christian Hansen, Hørsholm, Denmark) and sugar $10 \%$ (by mass per volume) in a reactor for yogurt and milk drinks (Mec Milk, São Paulo SP, Brazil). The ingredients were mixed until complete dissolution was reached and incubated at $42{ }^{\circ} \mathrm{C}$ for $5 \mathrm{~h}$ in a jacketed, thermostated system with the capacity of $50 \mathrm{~L}$. At the end of the process, the product was cooled to $4{ }^{\circ} \mathrm{C}$ and stored in the refrigerator for complete maturation of the mass. After processing, the yogurt was divided into three lots and the following were added: $0.05 \%$ of lyophilised anthocyanin extract without maltodextrin with $\mathrm{DE}=20$, $0.05 \%$ of lyophilised anthocyanin extract microencapsulated with maltodextrin, and the last without the addition of anthocyanins.

The colour analysis was performed using a colourimeter (model CR 400; Konica Minolta, Shanghai, China) to determine the $L^{*}, a^{*}$ and $b^{*}$ values (CIELab coordinates). The $L^{*}$ axis represents the darkness and lightness coordinate, with values ranging from 0 (perfect black) to 100 (perfect white). The $a^{*}$ axis represents chromaticity coordinates, in which green signifies negative and red positive coordinates. The $b^{*}$ axis also represents chromaticity coordinates, in which yellow signifies positive and blue negative coordinates. The values for each sample of the three lots of yogurt were obtained by the average of ten readings, and the colour was measured at three-day intervals over a range of 1 to 23 days of storage at $4{ }^{\circ} \mathrm{C}$.

\section{Sensory analysis}

Sensory analysis was performed by the consumer acceptance test, considering the attributes of colour, flavour, texture and aroma. A group of 80 volunteer judges, untrained and potential consumers of the product, evaluated the samples using a mixed structured hedonic scale of 9 points ( $1=$ extreme dislike and $9=$ extreme like). The samples were presented one by one, followed by a randomized complete block design (24). At the end of the sensory evaluation, a test was performed to estimate purchase intention, using a 5 point scale ( $1=$ definitely would not buy and $5=$ definitely would buy). To conduct the sensory tests, the present study was approved by the Standing Committee on Ethics in Research Involving Human Beings of Maringá State University, Brazil (protocol nos. CAAE 0339.0.093.000-11 and CAAE 0275.0.093.000-11). All panellists signed the consent form.

\section{Statistical analysis}

The results of the sensory analysis were submitted to analysis of variance (ANOVA) and mean values were compared using the 'post-hoc' Tukey's test, with the help of the STATISTICA ${ }^{\circledR}$ program, v. 8.0/2008 (StatSoft Inc., Tulsa, OK, USA). The level of significance for rejecting the null hypothesis was $5 \%(\mathrm{p}<0.05)(1)$.

\section{Results and Discussion}

\section{Determination of total anthocyanins in the juçara palm fruit extract}

The anthocyanin content can differ among various types of plants, season, climate, soil and other factors (2). In the present study it was $14340.20 \mathrm{mg} / \mathrm{L}$. This showed that the high concentration of anthocyanins obtained from the pulp of juçara palm fruit has a potential for use as a colouring agent and can be used in the preparation of different food products. In previous studies, the anthocyanin content was shown to be 2100, 39461.4, 480.6 and $882 \mathrm{mg} / \mathrm{L}$ in grape juice (Vitis labrusca L.), açaí pulp (Euterpe oleracea Mart.), jaboticaba (Myrciaria cauliflora) and pomegranate (Punica granatum), respectively $(5,20,25)$.

\section{Efficiency of the microencapsulation of anthocyanins}

The use of lyophilisation as an encapsulation method is recommended for compounds that are sensitive to heat degradation. In this research, the efficiency of the microencapsulation process was $93.6 \%$, which is higher than that found by Laine et al. (14), who used the anthocyanin extract of wild blackberry (Rubus chamaemorus). When these authors used maltodextrins with $\mathrm{DE}=5-8$ and 18.5 in the proportion of 1:9 as the matrix, the lyophilisation process showed an efficiency of 79 and $48 \%$, respectively. Robert et al. (20) worked with the juice and ethanolic extract of pomegranate and used the technique of microencapsulation by spray drying with isolated soya protein and maltodextrin with $\mathrm{DE}=12-20$ as encapsulating agents. These authors found a minimum microencapsulation ef- 
ficiency of $35.8 \%$ of pomegranate juice with soya protein isolate, $89.4 \%$ of pomegranate juice with maltodextrin, $73.0 \%$ of ethanolic extract with soya protein isolate and $96.7 \%$ of ethanolic extract with maltodextrin. The values found in the literature demonstrate the ability of maltodextrin to link up with anthocyanins, forming an interaction with the flavylium cation (20) and thus acting as good encapsulating agents for pigments.

\section{Heat stability of anthocyanins}

Among the factors that degrade anthocyanins, the temperature used during processing of food has the greatest influence. Fig. 1 shows the results of heat treatment at different temperatures of the anthocyanin extract microencapsulated with maltodextrin.

In Figs. 1a and $b$, the stability of the anthocyanins encapsulated with maltodextrin with $\mathrm{DE}=20$ at temperatures of 60 and $70{ }^{\circ} \mathrm{C}$ can be observed; therefore, it can be concluded that maltodextrin acted as a barrier to the degradation of the samples and their colour change. Changes in the colouration occur with the formation of undesirable and colourless compounds $(9,26)$.

For treatment at temperatures of 80 and $90^{\circ} \mathrm{C}$, as shown in Figs. 1c and d, respectively, quantitative differences in the retention of anthocyanins were observed in both formulations, with and without maltodextrin, which shows that anthocyanins are sensitive to high temperatures $(\geq 80$ $\left.{ }^{\circ} \mathrm{C}\right)$. The results confirm that higher temperatures act as catalysts in oxidation reactions, and greater degradation occurs with increasing temperature, which leads to the loss of anthocyanin stability. Hydrolysis of the glycosidic bonds in the molecules, the formation of chalcones and subsequent loss of colouration, reducing its colouring power are more frequent at high temperatures $(14,25)$.

Burin et al. (1) optimised the extraction of anthocyanins from Cabernet Sauvignon grape juice and performed microencapsulation with maltodextrin. They reported low values of preservation when only maltodextrin was used in the microencapsulation process, because the ability of the matrix to form film was weak, affecting the formation of the microcapsules and, consequently, their heat stability. Amr and Al-Tamimi (27) investigated Ranunculus asiaticus extracts and reported that after heating at 50 and $80{ }^{\circ} \mathrm{C}, \mathrm{pH}=3.5$, the percentages of remaining anthocyanins were 58 and $52 \%$, respectively.

\section{Colouration of anthocyanins at different $p H$}

In acidic solutions, anthocyanins are in their flavylium cation form $\left(\mathrm{AH}^{+}\right)$, and the red colour predominates. When the $\mathrm{pH}$ increases, it causes a conformational change of anthocyanins because the cation loses a proton, undergoes hydration and changes to a pseudobase or carbinol. When the reaction reaches equilibrium, the anthocyanin is in a colourless form. Therefore, the relative amounts of each structure present in the anthocyanin extract vary depending on the $\mathrm{pH}$ (12). These results are consistent with studies by Wang et al. (21) who showed that blueberry anthocyanins were stable at low $\mathrm{pH}$ (5.0) but were sensitive to an alkaline environment, high temperature, light, oxidants and reductants. Variations in $\mathrm{pH}$ may cause chang-

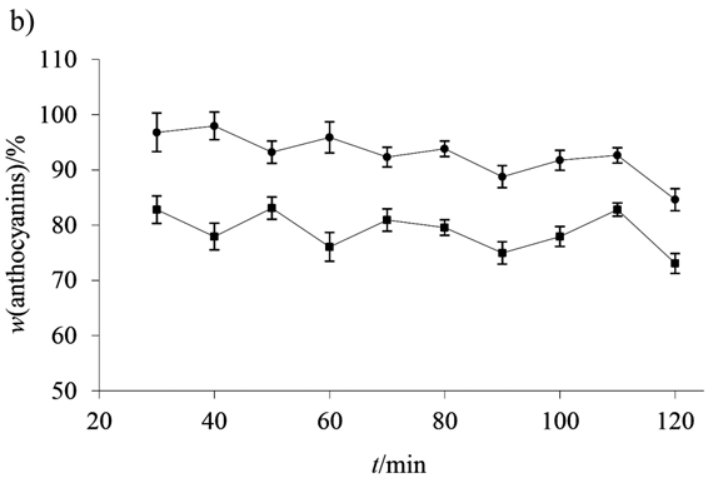

d)

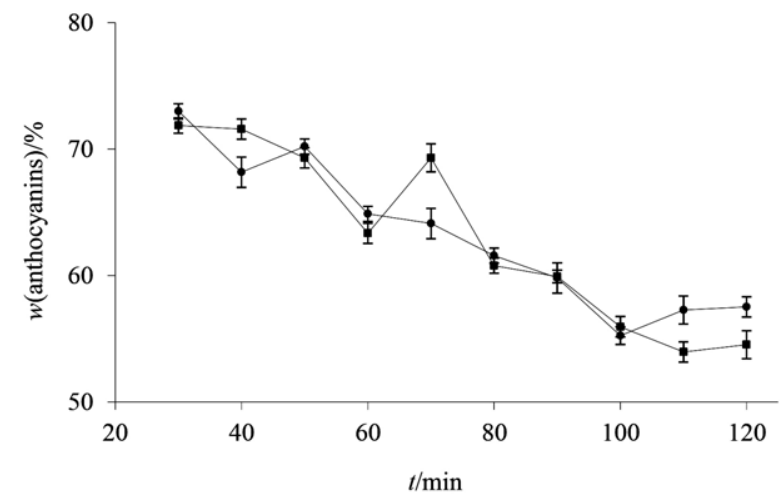

Fig. 1. Mass fractions of the lyophilised anthocyanin extract (-m-) and lyophilised anthocyanin extract microencapsulated with maltodextrin (-๑-) after heating at different temperatures: a) 60, b) 70, c) 80 and d) $90{ }^{\circ} \mathrm{C}$ 
es in colouration and thus a mischaracterisation of the product (3); therefore, $\mathrm{pH}$ is a limiting factor in anthocyanin use in foods, and the extracts and microcapsules produced in this study were tested at different $\mathrm{pH}$ values (Fig. 2).

A reduction in colouration from $\mathrm{pH}=1.5$ to 5.0 was observed in all samples and after that it did not change significantly until $\mathrm{pH}=9.0$. The use of microcapsules intensified the colouration by approx. $14 \%$ compared to non-microencapsulated extract at various $\mathrm{pH}$ values, most likely due to the interaction between the maltodextrin molecules and the anthocyanin structure (Fig. 2a).

After eight days of storage, the absorbance values of both extracts and microcapsules at $\mathrm{pH}=1.5,3.0$ and 5.0 were practically constant (Fig. 2b). It was observed that at various $\mathrm{pH}$ values, the colour of microcapsules intensified for approx. $16 \%$. Wang et al. (21) evaluated an anthocyanin extract from blueberries (Vaccinium corymbosum) at $\mathrm{pH}<5.0$ and observed the absorbance values similar to those found in the present study.

\section{Morphology of samples}

The morphology is different when using different methods of microencapsulation (28). The lyophilisation method has a great influence on the structure formed after drying. The morphological characterisation of the samples was performed using scanning electron microscopy (Fig. 3). Smooth microcapsules and flakes were observed in the form of microencapsulated complexes (Fig. 3c) and were similar to those reported by Laine et al. (14). The images show that the structure of anthocyanins changed from an amorphous morphology to a crystalline product with a more defined shape. The morphological changes may have been responsible for the increased dispersal of anthocyanins after microencapsulation, as was observed in the preparation of yogurt with lyophilised anthocyanin extract microencapsulated with maltodextrin.

\section{Thermograms of anthocyanin extracts before and after microencapsulation}

The differential scanning calorimetry (DSC) thermograms shown in Fig. 4a compare the lyophilised anthocyanin extract, the maltodextrin and the lyophilised anthocyanin extract microencapsulated with maltodextrin. The thermogram of maltodextrin shows peaks between 30-80 ${ }^{\circ} \mathrm{C}$, indicating a loss of water and evaporation of volatile compounds. The most pronounced endothermic peak at $245{ }^{\circ} \mathrm{C}$ was detected for maltodextrin and is related to the melting point of this molecule. Three endothermic peaks were observed for anthocyanins; the first and most intense at $120^{\circ} \mathrm{C}$, and two minor peaks near 400 and $450{ }^{\circ} \mathrm{C}$. a)

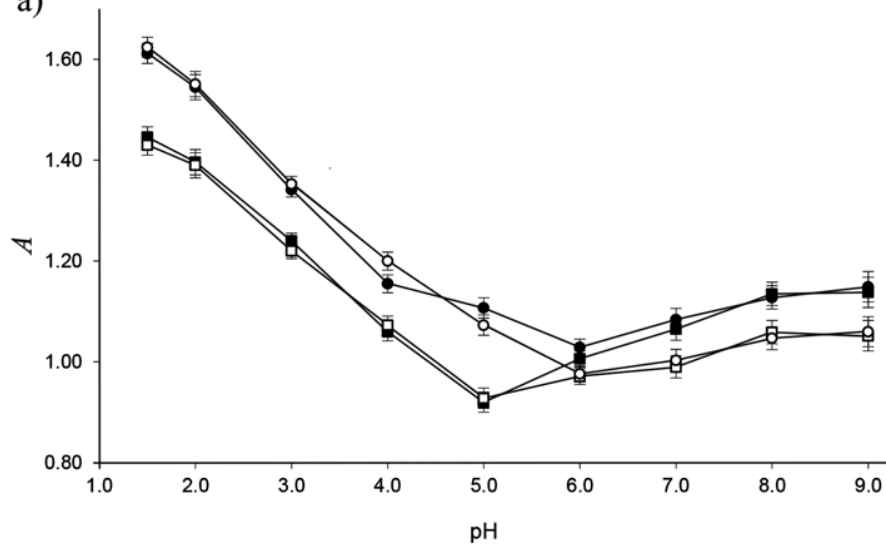

b)

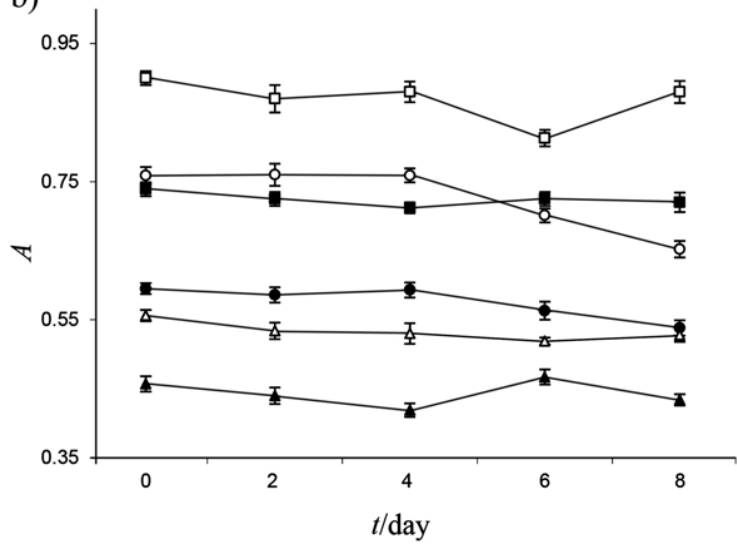

Fig. 2. Effect of $\mathrm{pH}$ on the stability of the absorbance measured at $520 \mathrm{~nm}$ : a) at pH=1.5 to 9.0, of lyophilised anthocyanin extract at

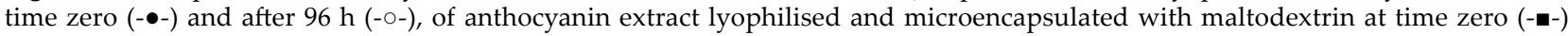

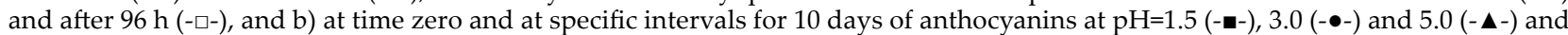
of microcapsules at $\mathrm{pH}=1.5(-\square-), 3.0(-\circ-)$ and $5.0(-\Delta-)$
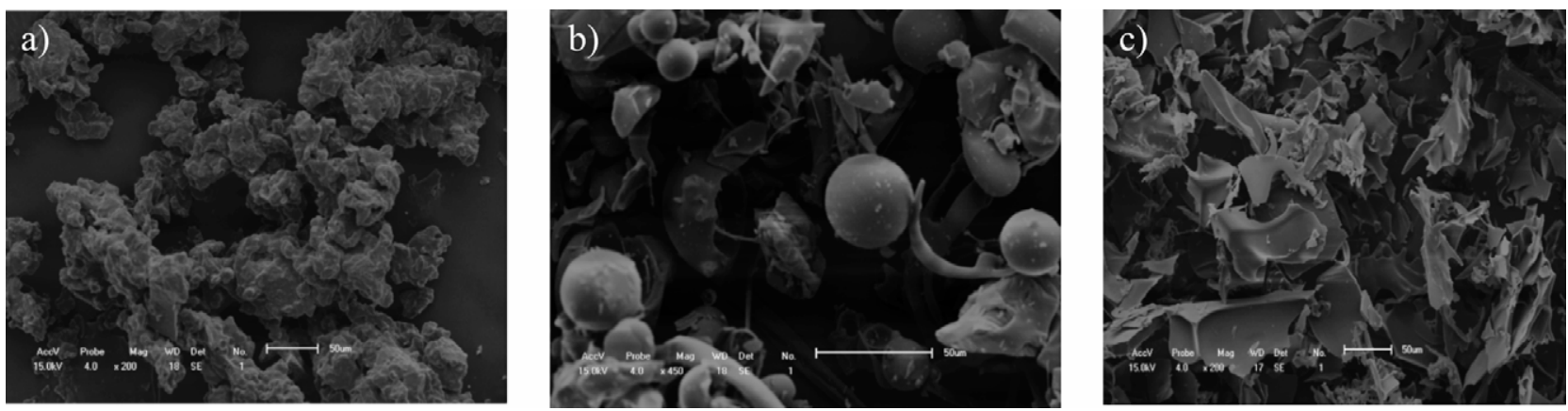

Fig. 3. Scanning electron microscopy of: a) lyophilised anthocyanin extract, b) maltodextrin with DE=20, and c) lyophilised anthocyanin extract microencapsulated with maltodextrin with $\mathrm{DE}=20$ 
The thermogram of the microencapsulated samples showed the peaks for both maltodextrin and anthocyanins. However, an enlargement of these peaks is evident, indicating the formation of a weak interaction, possibly due to maltodextrin molecules that do not form an effective complex with anthocyanins.

Fig. $4 \mathrm{~b}$ shows the results of thermogravimetric analysis of the same samples described above. The termogravimetric curves of maltodextrin and anthocyanins were similar to each other. Initially, the mass of the two samples decreased slightly, around $7 \%$, at temperatures between 20 and $115^{\circ} \mathrm{C}$. Therefore, this value is most likely related to water loss. In the temperature range between 115 and $220{ }^{\circ} \mathrm{C}$, the mass loss of maltodextrin was $3 \%$, and of anthocyanins $18 \%$, which is associated with the first endothermic peak observed by DSC $\left(120^{\circ} \mathrm{C}\right)$. At temperatures between 220 and $270{ }^{\circ} \mathrm{C}$, the mass loss of maltodextrin was $4 \%$ and of anthocyanins $13 \%$. This small mass change of maltodextrin confirms that the peak observed at $245^{\circ} \mathrm{C}$ in the DSC curve is due to the melting process and not caused by its degradation. Above $270{ }^{\circ} \mathrm{C}$, there was a highly significant mass loss of the maltodextrin sample due to its thermal degradation, which is associated with the peak occurring near $300{ }^{\circ} \mathrm{C}$ in the DSC curve, indicating that maltodextrin is unstable at temperatures above $100{ }^{\circ} \mathrm{C}$ and is degraded above $200{ }^{\circ} \mathrm{C}$, as reported by Osório et al. (29). Differences in the mass loss percentage of the samples of microencapsulated anthocyanins were observed at the same temperatures, because in the first stage, there was a mass loss of $8 \%$ followed by another $8 \%$. At temperatures between 220 and $270{ }^{\circ} \mathrm{C}$, the loss was $13 \%$, and a significant loss was observed above $270{ }^{\circ} \mathrm{C}$, which is related to the degradation of maltodextrin, as discussed above. At temperatures of approx. 115 ${ }^{\circ} \mathrm{C}$ the microcapsules were more thermally stable than the anthocyanins, a relevant fact because most foods are prepared at around this temperature.

The DSC thermograms of yogurt samples without the addition of anthocyanins, with the addition of anthocyanins and with the addition of anthocyanins microencapsulated with maltodextrin are shown in Fig. 5.

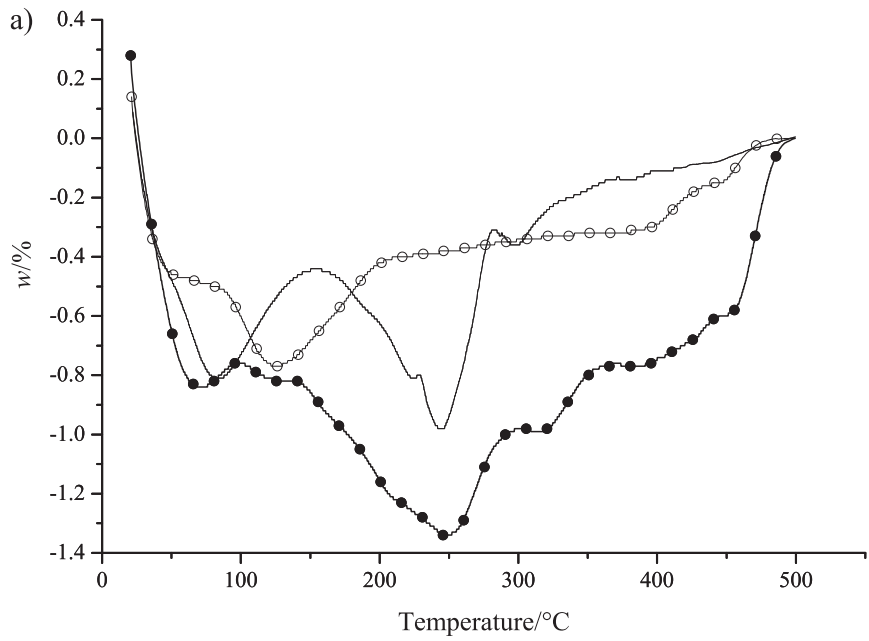

At the zero time point, the thermograms of the three samples were very similar, and it was possible to observe a markedly pronounced endothermic process at an onset temperature of approx. $100{ }^{\circ} \mathrm{C}$ and a peak temperature of $150^{\circ} \mathrm{C}$, which is associated with the degradation of different constituents of yogurt (Fig. 5a). The analyses of the samples after 10 days of storage showed the signs of degradation of the yogurt without the addition of anthocyanins, because the onset temperature shifted to approx. 50 ${ }^{\circ} \mathrm{C}$, while the other samples remained unchanged (Fig. $5 b$ ). This degradation of the sample without anthocyanins can be attributed to products made with fermented milk. The fermentation process causes significant changes in the composition of the final yogurt, such as changes in the aroma, flavour and acidity of the milk, as described by Cheng (30).

In the measurements performed after 20 days of storage, in the samples with and without anthocyanins, a second endothermic process was observed at temperatures near room temperature (Fig. 5c). The appearance of this peak is most likely related to the melting process of fat present in the milk, as described by Hu et al. (31). A slight reduction in the peak temperature region at $150{ }^{\circ} \mathrm{C}$ was also observed in these samples, while the thermogram of the yogurt with encapsulated anthocyanins remained unchanged.

After 30 days of storage, a significant reduction in the onset temperature of the yogurt with microencapsulated anthocyanins was observed (Fig. 5d) which was similar to that of the yogurt without anthocyanins at 10 days of storage. This indicates a delay in the degradation process and possible preservation of the yogurt characteristics in the sample with microencapsulated anthocyanins, which is probably a result of the interaction of anthocyanins and maltodextrin with yogurt components.

Fig. 6 shows the results of TGA of the yogurt samples without the addition of anthocyanins, with the addition of anthocyanins and with anthocyanins microencapsulated with maltodextrin.

Similar to what was observed in DSC, the thermogravimetric curves of all of the samples were initially sim-

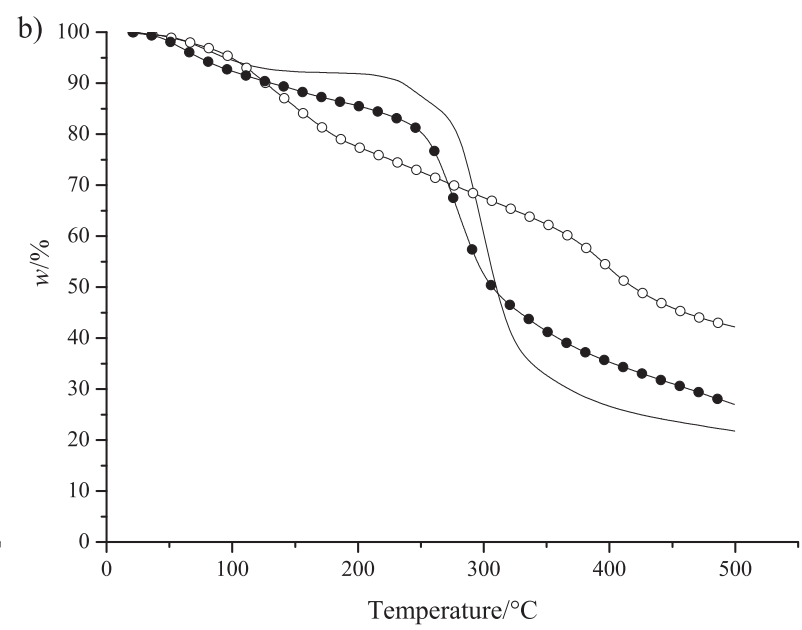

Fig. 4. Thermograms of: a) differential scanning calorimetry, and b) thermogravimetry of the lyophilised anthocyanin extract (-o-), maltodextrin with $\mathrm{DE}=20(-)$, and lyophilised anthocyanin extract microencapsulated with maltodextrin with $\mathrm{DE}=20(-\bullet-)$ 

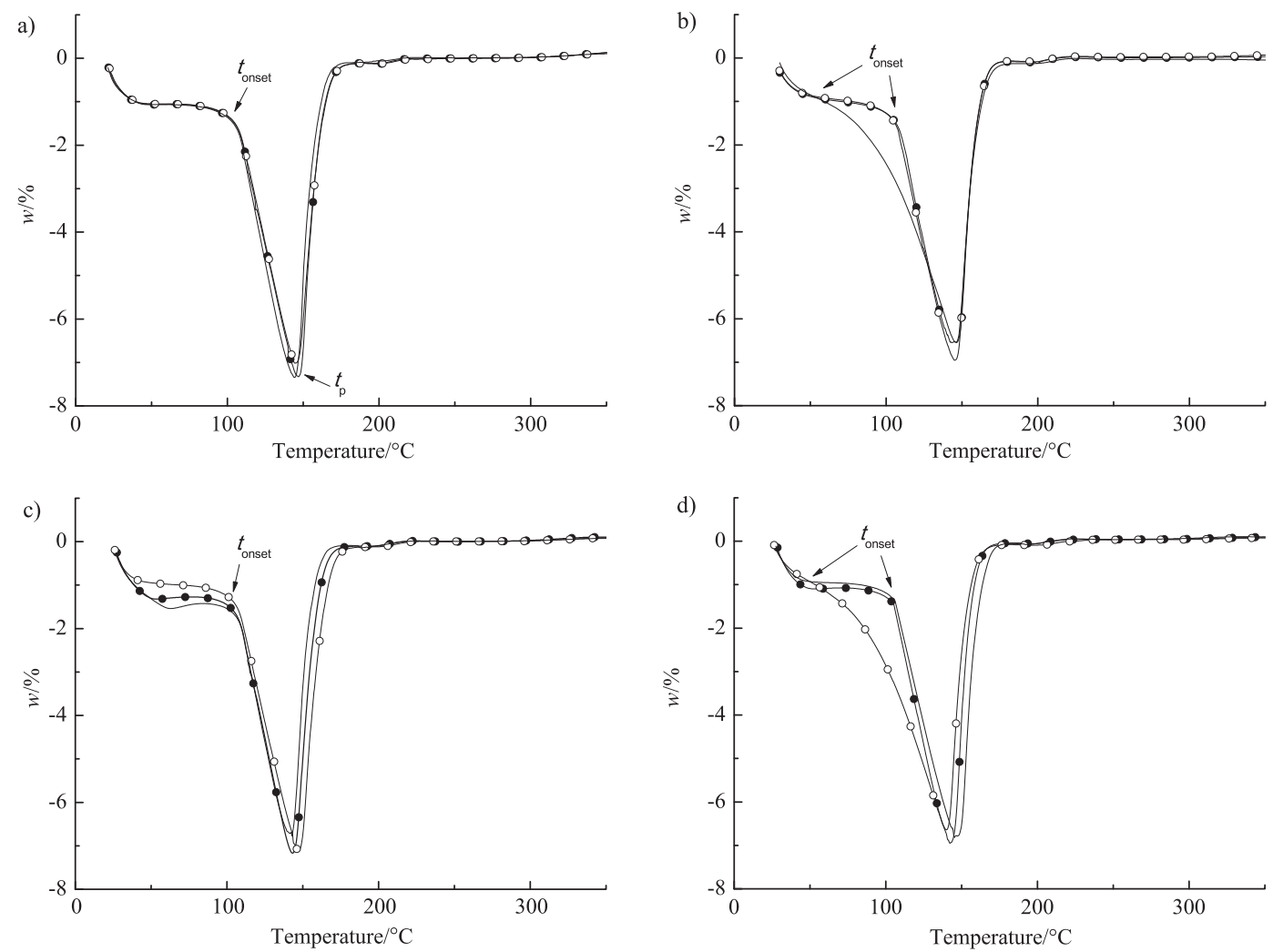

Fig. 5. Thermograms of differential scanning calorimetry of the samples of yogurt without the addition of anthocyanins (-), yogurt with the addition of anthocyanins (-•-) and yogurt with microencapsulated anthocyanins (-o-) at: a) time zero, b) 10 days of storage, c) 20 days of storage, and d) 30 days of storage. $t_{\text {onset }}=$ onset temperature, $t_{\mathrm{p}}=$ peak temperature
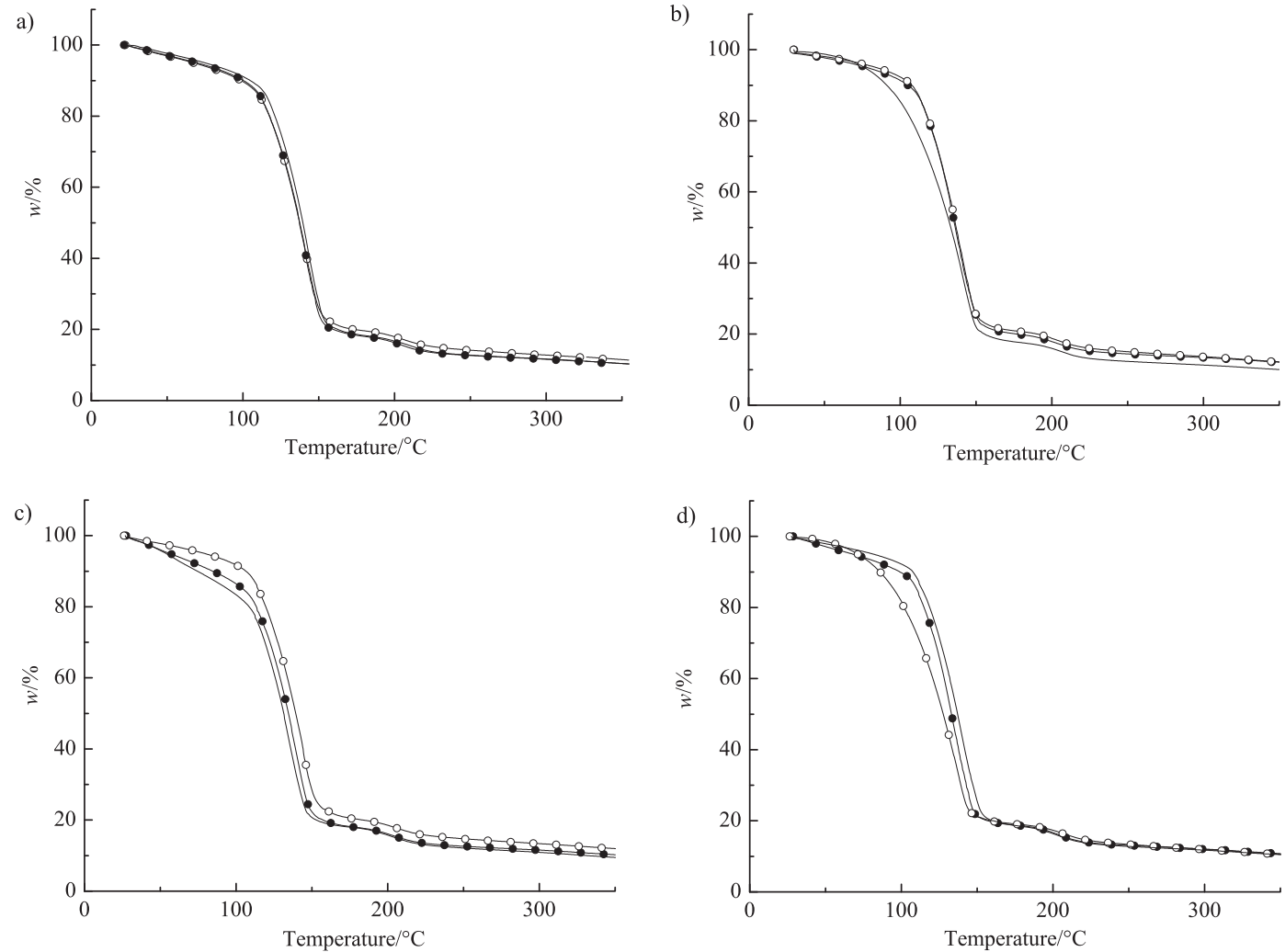

Fig. 6. Results of thermogravimetric analyses of the samples of yogurt without the addition of anthocyanin (-), yogurt with the addition of anthocyanins (- $\bullet$-) and yogurt with the addition of microencapsulated anthocyanins (-०-) at: a) time zero, b) 10 days of storage, c) 20 days of storage, and d) 30 days of storage 
ilar to each other, with a mass loss of approx. $10 \%$ between 25 and $100{ }^{\circ} \mathrm{C}$, which is related to the loss of liquid present in the samples (Fig. 6a). In the interval between 100 and $150{ }^{\circ} \mathrm{C}$ the samples showed a pronounced decrease of $70 \%$, demonstrating a high mass loss associated with the endothermic peak detected using DSC (peak temperature of $150{ }^{\circ} \mathrm{C}$ ), indicating thermal degradation of products. At temperatures between 150 and $230{ }^{\circ} \mathrm{C}$ there was a lower mass loss as a result of the degradation of by-products, and at $350{ }^{\circ} \mathrm{C}$ the mass loss was approx. $90 \%$.

At 10 days of storage (Fig. 6b), a more pronounced mass loss of the sample without anthocyanins occurred at lower temperatures, confirming the decrease of the onset temperature measured using DSC. Moreover, this sample had a higher total mass loss than the others, which confirms the formation of more volatile products due to the fermentation of yogurt. Measurements at 20 days of storage (Fig. 6c) produced thermograms showing that the sample with the microencapsulated anthocyanins retained its initial characteristics, while the other samples had a higher mass loss in the region between 25 and 100 ${ }^{\circ} \mathrm{C}$, reaching $20 \%$ of yogurt without anthocyanins, twice the value observed of yogurt with microcapsules.

At 30 days of storage (Fig. 6d), the greatest mass loss of the yogurt with microencapsulated anthocyanins was observed at much lower temperatures, which was similar to the results obtained for yogurt without anthocyanins at 10 days of storage, indicating a delay in the degradation process of the sample with microencapsulated anthocyanins. The results of TGA confirmed the DSC data, and it is possible to infer that the use of anthocyanins microencapsulated with maltodextrin can improve the thermal stability of food products by providing greater durability and shelf life, which is extremely important for the food industry.

\section{Photoacoustic signals of analyzed samples}

Fig. 7 shows the photoacoustic signals of the samples of lyophilised anthocyanin extract, lyophilised anthocyanin extract microencapsulated with maltodextrin, and maltodextrin. After exposure to white light for $2 \mathrm{~h}$, at all of the wavelengths tested, a change of the intensity of the photoacoustic signal of the samples of lyophilised anthocyanin extract and lyophilised anthocyanin extract microencapsulated with maltodextrin was observed. Maltodextrin did not efficiently protect the anthocyanin samples from light degradation, because there was an increase in the photoacoustic signal. This increase was observed up to $340 \mathrm{~nm}$, indicating that light induced a structural change of maltodextrin, which absorbs light in this region. Therefore, the spectra indicated that the anthocyanins were degraded when exposed to light, even when they were microencapsulated with maltodextrin. However, this behaviour did not occur in the maltodextrin sample that was lyophilised, most likely because the drying process modified the structure of the maltodextrin sample.

Fig. 8 shows the photoacoustic signals of the yogurt samples without the addition of anthocyanins, with the addition of anthocyanins and with anthocyanins microencapsulated with maltodextrin. After the exposure to light,

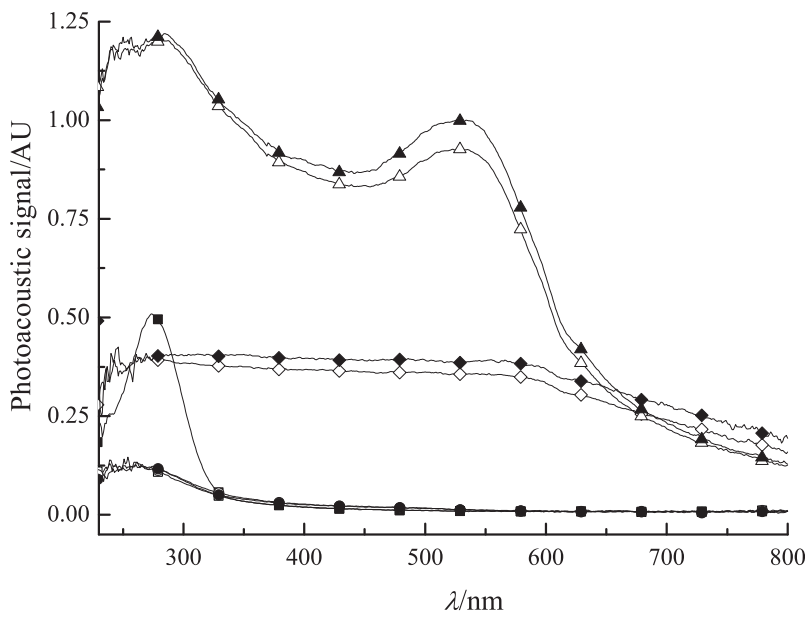

Fig. 7. Absorption spectra in the UV-Vis region at time zero (white symbols) and after $2 \mathrm{~h}$ (black symbols) of exposure to light of the samples of maltodextrin (- $\square-)$ and (-ø-), lyophilised anthocyanin extract $(-\diamond-)$ and $(-\bullet-)$, lyophilised anthocyanin extract microencapsulated with maltodextrin $(-\Delta-)$ and $(-\mathbf{\Delta}-)$, and

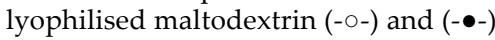

a change of the intensity of the photoacoustic signal of the samples was observed during the whole period. The absorption by the samples before exposure to white light was constant during the analysis period; however, changes of the signal intensity after exposure to white light for 2 $h$ occurred in all samples.

The yogurt without anthocyanins was modified when exposed to light, but with the addition of colourant, this change was greater because anthocyanins are highly unstable in the presence of light, even after the encapsulation with maltodextrin. In the sample containing anthocyanins, the increase in ligth absorption after $2 \mathrm{~h}$ occurred almost throughout the analyzed spectral range. Maltodextrin did not efficiently protect the anthocyanin sample from light degradation, indicating a weak interaction between anthocyanins and maltodextrin.

\section{Colourimetric analysis of yogurt containing anthocyanins}

The $\mathrm{pH}$ value is one of the most important factors for maintaining the colour of anthocyanins in food. The change in colour may be related to the complexation of the flavylium cation with maltodextrin, which retards the conversion into less stable forms $(3,21)$. All of the studied yogurt formulations had an initial $\mathrm{pH}=4.3$ and an end $\mathrm{pH}=4.2$. In acidic medium, the red colour predominates. As shown by the $a^{*}$ coordinate of the CIELab system, the sample with the microencapsulated powder had a $28.3 \%$ greater red colour intensity than the lyophilised sample containing only anthocyanins (Table 1). The sample containing microcapsules showed an $18.8 \%$ reduction in colour intensity during the study period. In addition, microencapsulation improved the incorporation of anthocyanins into the yogurt. Acidic products such as yogurt are promising targets for the incorporation of anthocyanins, due to the intrinsic characteristics of these natural colourants and the necessity of storage under refrigeration until consumption. 

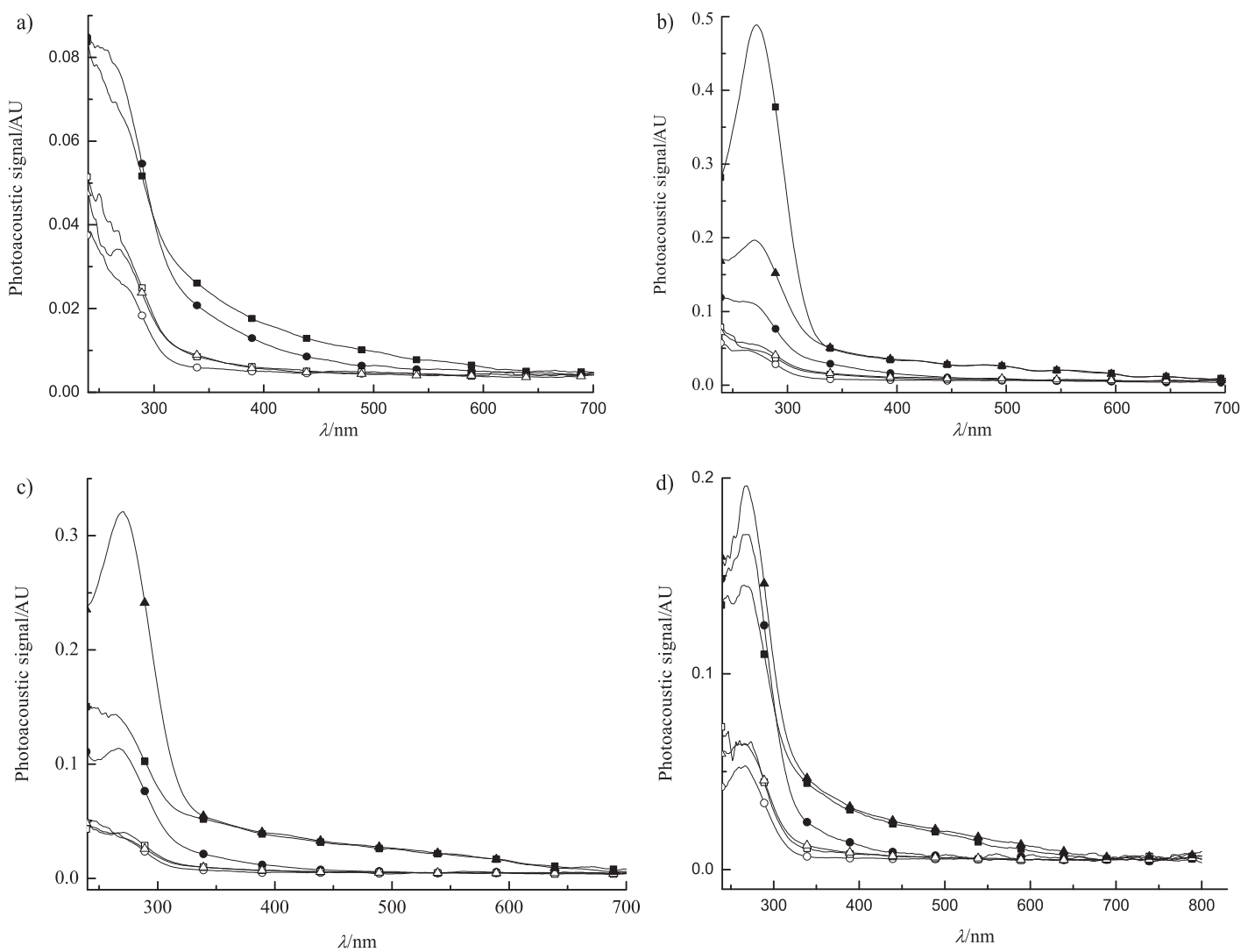

Fig. 8. Absorption spectra in the UV-Vis region of the samples of yogurt without anthocyanins before (-o-) and after (-๑-) exposure to light for $2 \mathrm{~h}$, yogurt with anthocyanins before (-口-) and after (-m-) exposure to light for $2 \mathrm{~h}$, and yogurt with microencapsulated anthocyanins before $\left(-\Delta^{-}\right)$and after (- $\left.\mathbf{\Delta}^{-}\right)$exposure to light for $2 \mathrm{~h}$ during: a) time zero, b) 10, c) 20, and d) 30 days of storage

Table 1. Colourimetric analysis of yogurt without the addition of anthocyanins, yogurt with the addition of anthocyanins and yogurt with the addition of microencapsulated anthocyanins during storage

\begin{tabular}{|c|c|c|c|c|c|c|c|c|c|}
\hline \multirow{2}{*}{ Yogurt sample } & \multicolumn{9}{|c|}{ t/day } \\
\hline & 1 & 2 & 5 & 8 & 11 & 14 & 17 & 20 & 23 \\
\hline \multicolumn{10}{|c|}{ without anthocyanins } \\
\hline$L^{*}$ & 88.16 & 87.92 & 87.71 & 87.84 & 88.95 & 87.87 & 88.22 & 88.15 & 88.42 \\
\hline$a^{*}$ & -2.57 & -3.26 & -3.32 & -3.22 & -3.30 & -3.21 & -3.13 & -3.14 & -3.16 \\
\hline$b^{*}$ & 8.91 & 9.99 & 9.60 & 10.48 & 10.39 & 10.13 & 9.91 & 10.69 & 10.44 \\
\hline \multicolumn{10}{|c|}{ with anthocyanins } \\
\hline$L^{*}$ & 76.89 & 78.17 & 77.62 & 78.50 & 78.52 & 78.38 & 78.91 & 77.62 & 76.77 \\
\hline$a^{*}$ & 3.80 & 3.71 & 3.64 & 3.52 & 3.60 & 3.47 & 3.41 & 3.27 & 3.03 \\
\hline$b^{*}$ & 6.04 & 7.13 & 7.21 & 7.59 & 7.65 & 7.66 & 7.69 & 7.60 & 7.73 \\
\hline \multicolumn{10}{|c|}{ with microcapsules } \\
\hline$L^{*}$ & 70.07 & 76.78 & 76.46 & 76.78 & 77.04 & 77.12 & 76.42 & 76.28 & 77.17 \\
\hline$a^{*}$ & 5.30 & 4.51 & 4.42 & 4.41 & 4.46 & 4.32 & 4.40 & 4.38 & 4.36 \\
\hline$b^{*}$ & 5.78 & 6.68 & 6.93 & 7.13 & 7.16 & 7.19 & 7.27 & 7.29 & 7.31 \\
\hline
\end{tabular}

$L^{*}=$ lightness, $a^{*}=$ green $/$ red,$b^{*}=$ blue/yellow

\section{Sensory scores of yogurt formulation}

The average values of the flavour, colour and texture of the tested yogurt formulations were not significantly different ( $>0.05$ ) (Table 2). This suggests that the addition of the lyophilised anthocyanin extract and lyophilised anthocyanin extract microencapsulated with malto- dextrin, used for the purpose of conferring red colour, did not affect the sensory characteristics as determined by the panellists, at least in the mass fraction used $(0.05 \%)$. The scores given for all attributes varied between 6.35 and 7.29 , which corresponds to the terms 'like slightly' and 'like very much' of the hedonic scale. 
Table 2. Mean values and standard deviation obtained for the flavour, colour and texture scores of yogurt formulations

\begin{tabular}{lccc}
\hline Attributes & $\begin{array}{c}\text { Yogurt without } \\
\text { anthocyanins }\end{array}$ & $\begin{array}{c}\text { Yogurt with } \\
\text { anthocyanins }\end{array}$ & $\begin{array}{c}\text { Yogurt with } \\
\text { microcapsules }\end{array}$ \\
\hline Flavour & $6.39 \pm 1.36$ & $6.35 \pm 1.38$ & $6.85 \pm 1.37$ \\
Colour & $6.35 \pm 1.71$ & $6.39 \pm 1.70$ & $7.10 \pm 1.44$ \\
Texture & $6.80 \pm 1.77$ & $6.79 \pm 1.76$ & $6.85 \pm 1.78$ \\
\hline
\end{tabular}

There was no significant difference between the samples $(p \leq 0.05)$. Scale used: $1=$ extremely dislike and $9=$ extremely like

The three yogurt products scored over $50 \%$ on the purchase intent scale. Similar values were obtained by Oliveira et al. (32), who studied the sensory acceptance and purchase intent of yogurt produced with araticum (Annona crassiflora Mart.) fruit pulp. These results demonstrate that yogurt formulated with lyophilised anthocyanin extract and lyophilised anthocyanin extract microencapsulated with maltodextrin will be well accepted on the market.

\section{Conclusions}

Using relevant techniques, such as differential scanning calorimetry (DSC), thermogravimetric analysis (TGA), scanning electron microscopy and photoacoustic spectroscopy, this study confirmed the possibility of stabilising anthocyanins from juçara palm fruit (Euterpe edulis Mart.) using lyophilisation and microencapsulation with maltodextrin with $\mathrm{DE}=20$ and its application in foods. With respect to heat treatment, maltodextrin with $\mathrm{DE}=20$ protected anthocyanins at temperatures up to $70{ }^{\circ} \mathrm{C}$ for $120 \mathrm{~min}$. At different $\mathrm{pH}$ values and storage times, the microcapsules obtained a colour intensity that was approx. $16 \%$ higher than of the anthocyanin extract without maltodextrin. Scanning electron microscopy confirmed that lyophilisation influences the structure of the microcapsules, because the morphology of the anthocyanins changed from an amorphous form to a product of crystalline aspect, with an appearance of thin and flat flakes. The thermal analyses (DSC and TGA) and photoacoustics were important tools in determining the behaviour of microencapsulated natural colourants and their potential use in food. DSC and TGA indicated the formation of weak interactions between anthocyanins and maltodextrin; however, at temperatures of approx. $115^{\circ} \mathrm{C}$, the microcapsules were more thermally stable than the anthocyanins without maltodextrin. Moreover, these techniques indicated a delay in the degradation process and possible maintenance of the characteristics of yogurt with microencapsulated anthocyanins. The photoacoustics showed that maltodextrin protected the anthocyanins from light degradation and suggested that lyophilisation may modify the structure of substances, as occurred with lyophilised maltodextrin. The anthocyanin extracts lyophilised with maltodextrin had a more intense colour than those without maltodextrin, and were better incorporated into the yogurt because of better solubilisation. Sensory analysis confirmed the possible application of microencapsulated anthocyanins as natural food colourants.

\section{Acknowledgements}

The authors thank the biotechnology company Solabia Group, Maringá, Paraná, Brazil, for donating the sample of the pulp of Euterpe edulis Mart., Coordination for the Improvement of Higher Education Staff (Capes) for the scholarship, and National Council for Scientific and Technological Development (CNPq) and Araucária Foundation (FA) for the financial support.

\section{References}

1. Burin VM, Rossa PN, Ferreira-Lima NE, Hillmann MCR, Boirdignon-Luiz MT. Anthocyanins: optimisation of extraction from Cabernet Sauvignon grapes, microcapsulation and stability in soft drink. Int J Food Sci Tecnol. 2011;46:186-93. http://dx.doi.org/10.1111/j.1365-2621.2010.02486.x

2. Selim KA, Khalil KE, Abdel-Bary MS, Abdel-Azeim NA. Extraction, encapsulation and utilization of red pigments from roselle (Hibiscus sabdariffa L.) as natural food colourants. Alex J Food Sci Technol. Conf. Vol. 2008; 7-20.

3. Bakowska-Barczak A. Acylated anthocyanins as stable, natural food colorants: a review. Pol J Food Nutr. Sci. 2005;55:10716.

4. Valduga E, Lima L, Prado R, Padilha FF, Treichel H. Extraction, spray drying and microencapsulating of Isabel grape (Vitis labrusca L.) bagasse anthocyanins. Ciênc Agrotec. 2008; 32:1568-74 (in Portuguese). http://dx.doi.org/10.1590/S1413-70542008000500032

5. Bordignon-Luiz MT, Gauche C, Gris EF, Falcão LD. Colour stability of anthocyanins from Isabel grapes (Vitis labrusca L.) in model systems. LWT - Food Sci Technol. 2007;40:594-9. http://dx.doi.org/10.1016/j.lwt.2006.02.022

6. Iaderoza M, Baldini VLS, Draetta I dos S, Bovi MLA. Anthocyanins from fruits of açaí (Euterpe oleracea, Mart) and juçara (Euterpe edulis Mart). Trop Sci.1999;32:41-6.

7. Estupiñan DC, Schwartz SJ, Garzón GA. Antioxidant activity, total phenolics content, anthocyanin, and color stability of isotonic model beverages colored with Andes berry (Rubus glaucus Benth) anthocyanin powder. J Food Sci. 2011;76:26-34. http://dx.doi.org/10.1111/j.1750-3841.2010.01935.x

8. Castañeda-Ovando A, Pacheco-Hernández ML, Páez-Hernández ME, Rodríguez JA, Galán-Vidal C. Chemical studies of anthocyanins: a review. Food Chem. 2009;113:859-71. http://dx.doi.org/10.1016/j.foodchem.2008.09.001

9. Patras A, Brunton NP, O'Donnell C, Tiwari BK. Effect of thermal processing on anthocyanin stability in foods; mechanisms and kinetics of degradation. Trends Food Sci Technol. 2010;21:3-11. http://dx.doi.org/10.1016/j.tifs.2009.07.004

10. Mourtzinos I, Makris DP, Yannakopoulou K, Kalogeropoulos N, Michali I, Karathanos VT. Thermal stability of anthocyanin extract of Hibiscus sabdariffa L. in the presence of beta-cyclodextrin. J Agric Food Chem. 2008;56:10303-10. http://dx.doi.org/10.1021/jf801389j

11. Ersus S, Yurdagel U. Microencapsulation of anthocyanin pigments of black carrot (Daucus carota L.) by spray drier. J Food Eng. 2007;80:805-12. http://dx.doi.org/10.1016/j.jfoodeng.2006.07.009

12. Cavalcanti RN, Santos DT, Meireles MA. Non-thermal stabilization mechanisms of anthocyanins in model and food systems - an overview. Food Res Int. 2011;44:499-509. http://dx.doi.org/10.1016/j.foodres.2010.12.007

13. Tonon RV, Baroni AF, Brabet C, Gibert O, Pallet D, Hubinger MD. Water sorption and glass transition temperature of 
spray dried açai (Euterpe oleracea Mart.) juice. J Food Eng. 2009;94:215-21.

http://dx.doi.org/10.1016/j.jfoodeng.2009.03.009

14. Laine P, Kylli P, Heinonen M, Jouppila K. Storage stability of microencapsulated cloudberry (Rubus chamaemorus) phenolics. J Agr Food Chem. 2008;56:11251-61. http://dx.doi.org/10.1021/jf801868h

15. Fang Z, Bhandari B. Effect of spray drying and storage on the stability of bayberry polyphenols. Food Chem. 2011;129: 1139-47. http://dx.doi.org/10.1016/j.foodchem.2011.05.093

16. Nayak CA, Rastogi NK. Effect of selected additives on microencapsulation of anthocyanin by spray drying. Drying Technol. 2010;28:1396-404.

http://dx.doi.org/10.1080/07373937.2010.482705

17. Coelho TM, Vidotti EC, Rollemberg MC, Medina AN, Baesso ML, Cella N, Bento AC. Photoacoustic spectroscopy as a tool for determination of food dyes: comparison with first derivative spectrophotometry. Talanta. 2010;81:202-7. http://dx.doi.org/10.1016/j.talanta.2009.11.058

18. Teixeira LN, Stringheta PC, Oliveira FA. Comparation of methods for anthocyanin quantification. Rev Ceres. 2008;55: 297-304 (in Portuguese).

19. Lee J, Durst RW, Wrolstad RE. Determination of total monomeric anthocyanin pigment content of fruit juices, beverages, natural colorants, and wines by the $\mathrm{pH}$ differential method: collaborative study. J AOAC Int. 2005;88:1269-78.

20. Robert P, Gorena T, Romero N, Sepulveda E, Chavez J, Saenz C. Encapsulation of polyphenols and anthocyanins from pomegranate (Punica granatum) by spray drying. Int J Food Sci Technol. 2010;45:1386-94. http://dx.doi.org/10.1111/j.1365-2621.2010.02270.x

21. Wang BC, He R, Li ZM. The stability and antioxidant activity of anthocyanins from blueberry. Food Technol Biotechnol. 2010;48:42-9.

22. Dias HMAM, Berbicz F, Pedrochi F, Baesso ML, Matioli G. Butter cholesterol removal using different complexation methods with beta-cyclodextrin, and the contribution of photoacoustic spectroscopy to the evaluation of the complex. Food Res Int. 2010;43:1104-10. http://dx.doi.org/10.1016/j.foodres.2010.02.002
23. Rensis CMVB, Souza PFF. Sensorial analysis of light yoghurt with dietary fibers. Eng Alim Food Eng. 2008;5:68-72 (in Portuguese).

24. Lawless HT, Heymann H. Sensory evaluation of food - Principles and practices. New York, NY, USA: Springer; 2004. pp. 235-378.

25. Tonon RV, Brabet C, Hubinger MD. Anthocyanin stability and antioxidant activity of spray-dried açaí (Euterpe oleracea Mart.) juice produced with different carrier agents. Food Res Int. 2010;43:907-14. http://dx.doi.org/10.1016/j.foodres.2009.12.013

26. Kirca A, Ozkan M, Cemeroglu B. Effects of temperature, solid content and $\mathrm{pH}$ on the stability of black carrot anthocyanins. Food Chem. 2007;101:212-8.

http://dx.doi.org/10.1016/j.foodchem.2006.01.019

27. Amr A, Al-Tamimi E. Stability of the crude extracts of Ranunculus asiaticus anthocyanins and their use as food colourants. Int J Food Sci Technol. 2007;42:985-91. http://dx.doi.org/10.1111/j.1365-2621.2006.01334.x

28. Che Man YB, Irwandi J, Abdullah WJW. Effect of different types of maltodextrin and drying methods on physicochemical and sensory properties of encapsulated durian flavor. J Sci Food Agric. 1999;79:1075-80. http://dx.doi.org/10.1002/(SICI)1097-0010(199906)79:8<1075: AID-JSFA329>3.0.CO;2-Q

29. Osório C, Acevedo B, Hillebrand S, Carriazo J, Winterhalter P, Morales AL. Microencapsulation by spray-drying of anthocyanin pigments from corozo (Bactris guineensis) fruit. J Agric Food Chem. 2010;58:6977-85. http://dx.doi.org/ 10.1021/jf100536g

30. Cheng H. Volatile flavor compounds in yogurt: a review. Crit Rev Food Sci Nutr. 2010;50:938-50. http://dx.doi.org/10.1080/10408390903044081

31. Hu J, Sari O, Eicher S, Rakotozanakajy AR. Determination of specific heat of milk at different fat content between $1^{\circ} \mathrm{C}$ and $59^{\circ} \mathrm{C}$ using micro DSC. J Food Eng. 2009;90:395-9. http://dx.doi.org/10.1111/j.1471-0307.2008.07.009

32. Oliveira KAM, Ribeiro LS, Oliveira GV, Pereira JMATK, Mendonça CS, Assumpção CF. Development of araticum yogurt formulation and sensory acceptance study. Alim Nutr. 2008;19:277-81 (in Portuguese). 